\title{
Grape seed proanthocyanidin extract protects from cisplatin-induced nephrotoxicity by inhibiting endoplasmic reticulum stress-induced apoptosis
}

\author{
ZHAOLI GAO $^{1 *}$, GUANGYI LIU $^{1,2^{*}}, \mathrm{ZHAO} \mathrm{HU}^{1}, \mathrm{XING} \mathrm{LI}^{1}$, \\ XIANGDONG YANG ${ }^{1}$, BEI JIANG ${ }^{1}$ and XIANHUA LI ${ }^{1}$ \\ ${ }^{1}$ Department of Nephrology, Qi Lu Hospital of Shandong University; ${ }^{2}$ Ministry of \\ Education Key Laboratory of Experimental Teratology and Institute of Molecular Medicine and \\ Genetics, Shandong University School of Medicine, Jinan, Shandong 250012, P.R. China
}

Received October 14, 2013; Accepted December 16, 2013

DOI: $10.3892 / \mathrm{mmr} .2014 .1883$

\begin{abstract}
Cisplatin (CP) is used as an antineoplastic drug in the clinic, but its nephrotoxicity limits its use. Grape seed proanthocyanidin extract (GSPE) is a powerful antioxidant. In this study, we investigated whether GSPE can prevent $\mathrm{CP}$-induced nephrotoxicity and explored the underlying mechanism. Male C57/BL6 mice were randomly divided into four groups: control group (N), CP group (C), receiving an intraperitoneal (ip) injection of $20 \mathrm{mg} / \mathrm{kg} \mathrm{CP}$, GSPE group (G), receiving an intragastric (ig) dose of $500 \mathrm{mg} / \mathrm{kg}$ GSPE, and $\mathrm{CP}+\mathrm{GSPE}$ group $(\mathrm{C}+\mathrm{G})$, where ig administration of GSPE was performed $30 \mathrm{~min}$ prior to ip injection of $\mathrm{CP}$, followed by an additional ig administration of GSPE $72 \mathrm{~h}$ later. Blood and kidney samples were collected $120 \mathrm{~h}$ after treatment. The pathological changes in the kidney were examined by periodic acid-Schiff (PAS) staining, while the protein levels of glucose-regulated protein 78 (GRP78), phosphorylated-extracellular signal-regulated kinase ( $p$-ERK) and caspase-12 were examined by western blotting and immunohistochemical staining. Apoptosis was examined by a terminal deoxynucleotidyl transferase dUTP nick-end labeling (TUNEL) assay. Compared to the $\mathrm{CP}$ group, the $\mathrm{CP}+\mathrm{GSPE}$ group had a significant decrease in the level of blood urea nitrogen (BUN), serum creatinine (Scr) and reduced renal index (RI) $(\mathrm{P}<0.05)$, and showed limited histopathological damage. The
\end{abstract}

Correspondence to: Professor Xianhua Li, Department of Nephrology, Qi Lu Hospital of Shandong University, 107 Wenhua Xi Road, Jinan, Shandong 250012, P.R. China

E-mail: lixianhua@medmail.com.cn

Abbreviations: CP, cisplatin; GSPE, grape seed proanthocyanidin extract; ER, endoplasmic reticulum; GRP78, glucose-regulated protein 78; BUN, blood urea nitrogen; Scr, serum creatinine; RI, renal index; AKI, acute kidney injury

*Contributed equally

Key words: apoptosis, cisplatin, endoplasmic reticulum stress, grape seed proanthocyanidin extract, nephrotoxicity number of TUNEL-positive cells was significantly reduced in the $\mathrm{CP}+\mathrm{GSPE}$ group compared to the $\mathrm{CP}$ group $(\mathrm{P}<0.05)$, and the protein expression of GRP78, p-ERK and caspase-12 was significantly reduced in the $\mathrm{CP}+\mathrm{GSPE}$ group $(\mathrm{P}<0.05)$. We conclude that GSPE can protect the renal function from $\mathrm{CP}$-induced nephrotoxicity and can attenuate the endoplasmic reticulum (ER) stress-induced apoptosis via regulation of the caspase-12 pathway.

\section{Introduction}

Cisplatin (CP) or cis-Diamminedichloroplatinum (II), is widely used as an antitumor agent for the treatment of testis, bladder, lung and ovarian cancer. However, severe side-effects such as acute kidney injury (AKI), gastrointestinal toxicity, and ototoxicity limit its use in the clinic. In particular, AKI is a major side-effect (1-4). CP is toxic to the renal proximal tubules $(1,5,6)$. The nephrotoxic potential of $\mathrm{CP}$ is multifactorial, with the major factor being the induction of tubular cell apoptosis. The induction of tubular cell apoptosis by $\mathrm{CP}$ has been intensively investigated in the past decades. A number of apoptotic pathways have been examined, including the intrinsic, extrinsic and endoplasmic reticulum (ER) stress pathways (7).

ER is a key organelle of eukaryotic cells, where lipid synthesis, protein folding (into tertiary and quaternary structures) and protein maturation occur. The ER senses and responds to homeostatic changes, with various stimuli, such as ischemia, hypoxia, elevated protein synthesis and $\mathrm{Ca}^{+}$overload-inducing ER stress (8). The ER protein folding capacity is reduced under stress, leading to an accumulation of unfolded proteins. A major response to ER stress is the activation of the glucose-regulated protein 78 (GRP78) through dissociation from its transmembrane receptor, which allows subsequent regulation of the levels of accumulated unfolded proteins (9). Slight and medium ER stress can protect cells from death, but severe ER stress induces caspase-12-dependent cell apoptosis (10).

Numerous compounds have been experimentally shown to ameliorate cisplatin nephrotoxity, including vitamin E, 
melatonin, furosemide, mannitol and erythropoietin. Grape seed proanthocyanindin extract (GSPE) is derived from grape seeds. It is shown to possess a variety of potent properties, such as antioxidant, anti-inflammatory and antitumor activities, and to mediate resistance to free radicals and protection from cardiovascular diseases (11-13). In this study, GSPE was used to treat the mouse model of CP-induced nephropathy, in order to examine its potential protective effect(s) and examine whether these effects are mediated by the inhibition of ER stress-induced apoptosis occurring in tubular cells.

\section{Materials and methods}

Reagents. CP was purchased from Sigma-Aldrich (St. Louis, MO, USA). Grape seed proanthocyanidin extract (purity $>96 \%$, lot no. G050412) was purchased from Tianjin Jianfeng Natural Product R\&D Co., Ltd. (Tianjin, China). Primary antibodies used in this study were: rabbit anti-GRP78, rabbit anti-caspase-12 (Abcam Ltd., Hong Kong, China), rabbit anti-p-ERK, rabbit anti-ERK (Cell Signaling Technology, Inc., Danvers, MA, USA) and mouse anti- $\beta$-actin (Santa Cruz Biotechnology, Inc., Santa Cruz, CA, USA). Anti-mouse and anti-rabbit secondary antibodies were purchased from Jackson ImmunoResearch Laboratories Inc. (West Grove, PA, USA). The In Situ Cell Death Detection kit (Roche Diagnostics, Indianapolis, IN, USA) was used for the terminal deoxynucleotidyl transferase dUTP nick-end labeling (TUNEL) assay.

Animals. Seventy adult (6-8 weeks-old) male C57/BL6 mice, weighing 20-25 g, were supplied by the Beijing Vital River Laboratory Animal Technology Co.,Ltd.(Beijing, China). Mice were housed separately in metal cages with a $12 \mathrm{~h}$ dark/light cycle and $40-70 \%$ relative humidity, at a $18-22^{\circ} \mathrm{C}$ temperature. Food and water were available ad libitum. All experiments were conducted in accordance with the NIH Guide for the Care and Use of Laboratory Animals.

Animal treatment. Animals were randomly divided into four groups: i) control group $(\mathrm{N} ; \mathrm{n}=10)$, which only received intraperitoneal (ip) injection of vehicle solution ( $0.9 \%$ saline; $10 \mathrm{ml} / \mathrm{kg}$ ); ii) CP group (C; $\mathrm{n}=20)$, which only received an ip injection of $20.0 \mathrm{mg} / \mathrm{kg} \mathrm{CP}$ (dissolved in $0.9 \%$ saline to reach a concentration of $2.0 \mathrm{mg} / \mathrm{ml})$; iii) GSPE group $(\mathrm{G} ; \mathrm{n}=15)$, which received a single intragastric (ig) administration of $500 \mathrm{mg} / \mathrm{kg}$ GSPE (dissolved in $0.9 \%$ saline to reach $50 \mathrm{mg} / \mathrm{ml}$ ); and iv) $\mathrm{CP}+\mathrm{GSPE}$ group $(\mathrm{C}+\mathrm{G} ; \mathrm{n}=20)$, which successively received ig administration of $500 \mathrm{mg} / \mathrm{kg}$ GSPE at $30 \mathrm{~min}$ before ip injection of CP, and ig administration of $500 \mathrm{mg} / \mathrm{kg}$ GSPE after ip injection of CP $72 \mathrm{~h}$.

The mice were sacrificed $120 \mathrm{~h}$ after the injection of $0.9 \%$ saline or CP. Prior to sacrifice, the mice were weighed and blood was collected from the endocanthion. From this sample, the serum was separated by centrifugation $\left(912 \mathrm{x}\right.$ g at $4^{\circ} \mathrm{C}$ for $20 \mathrm{~min}$ ) and stored at $-80^{\circ} \mathrm{C}$ until assayed. Both kidneys were immediately excised and weighed, then each kidney was cut in half by coronal position. Two sections of each excised kidney were stored at $-80^{\circ} \mathrm{C}$ for western blot analysis. The remaining sections were fixed in $4 \%$ buffered paraformaldehyde at $4^{\circ} \mathrm{C}$ and embedded in paraffin for histopathologic observation, immunohistochemical study and TUNEL assay.
Assessments of renal function. Blood urea nitrogen (BUN) and serum creatinine (Scr) levels were measured in a Cobas ${ }^{\circledR} 8000$ modular analyser (Roche Diagnostics) in Qilu Hospital, Shandong University. The renal index (RI) was calculated as: both kindeys' weight (g)/animal's weight (g) x100.

Histopathologic observation. The pathologic changes in the kidney were examined by periodic acid-Schiff (PAS) staining. One-fourth of the kidneys was immersion-fixed in $10 \%$ buffered formalin and embedded in paraffin to be further examined under a light microscope. Two $4-\mu \mathrm{m}$ thick sections were performed per animal at an interval of $100 \mu \mathrm{m}$ and were stained with PAS reagent. Tubular damage was scored as follows: Each section was examined in 5 fields, and the average percentage of the impaired renal tubules was then calculated. The results of renal tubular damage were transformed into an index of renal tubular necrosis, where no damage was assigned a 0 index; $<25 \%$ damage was assigned $1 ; 25-50 \%$ damage was assigned $2 ; 50-75 \%$ damage was assigned 3 and $>75 \%$ damage was assigned a 4 index.

Immunohistochemical study. For immunohistochemical analysis, tissue slices were microwaved for 10-15 min in $0.01 \%$ sodium citrate buffer ( $\mathrm{pH} 6.0$ ) to allow antigen retrieval. The tissue slices were cooled at room temperature or in iced water, and then washed with PBS three times. The tissue slices were immersed in $0.1 \%$ Triton X-100 for 15 min. To block endogenous peroxidase activity, the tissue slices were incubated with $3 \%$ hydrogen peroxide for $10 \mathrm{~min}$ in the dark. The tissue slices were then incubated with $10 \%$ goat serum for $60 \mathrm{~min}$ at $37^{\circ} \mathrm{C}$, and with primary antibody at $4^{\circ} \mathrm{C}$ overnight (anti-GRP78 1:200, anti-p-ERK 1:50, anti-caspase-12 1:100), while the sections serving as negative controls were incubated with PBS, instead of the primary antibody. All the sections were incubated with secondary antibodies for $60 \mathrm{~min}$ at $37^{\circ} \mathrm{C}$, and stained with 3,3'-diaminobenzidine (DAB) and hematoxylin. Semiquantitative analysis was performed on the colored sections using a computer imaging analysis system (Leica QWin V3 image analysis software; Leica Microsystems, Heidelberg, Germany). Briefly, 10 high-power fields (x400) per section were randomly selected and two sections per kidney were examined in each experiment. Specimens were scored according to the intensity of the dye color and the percentage of positively stained areas. Brown areas were considered as positive. The intensity of the dye color was graded as 0 (no color); 1 (light yellow); 2 (light brown) and 3 (brown), and the percentage of positively stained areas was graded as $0(<5 \%) ; 1(5-25 \%) ; 2$ (25-50\%); $3(51-75 \%)$ and $4(>75 \%)$. The two grades were added to give a final score of expression for each tested protein.

TUNEL assay. The TUNEL assay was conducted following the manufacturer's instructions. Sections were incubated with proteinase $\mathrm{K}$ at $37^{\circ} \mathrm{C}$ for $30 \mathrm{~min}$, then with the mix of enzyme and labeling solutions (1:9) at $37^{\circ} \mathrm{C}$ for $60 \mathrm{~min}$ in the dark. The sections serving as negative controls were incubated with labeling solution only. Sections were then stained with 4',6-diamidino-2-phenylindole (DAPI) for $10 \mathrm{~min}$. The number of TUNEL-positive nuclei was expressed as a percentage of total nuclei per field. Ten fields per section and two sections per kidney were examined in each experiment. 
Table I. Animal groups and related biochemical parameters.

\begin{tabular}{lcccc}
\hline Group & No. & RI & BUN & Scr \\
\hline $\mathrm{N}$ & 8 & $1.43 \pm 0.074$ & $10.19 \pm 1.17$ & $29.5 \pm 6.07$ \\
$\mathrm{C}$ & 15 & $1.79 \pm 0.066^{\mathrm{a}}$ & $30.85 \pm 6.74^{\mathrm{a}}$ & $135.13 \pm 12.64^{\mathrm{a}}$ \\
$\mathrm{G}$ & 13 & $1.41 \pm 0.068^{\mathrm{b}}$ & $10.23 \pm 1.44^{\mathrm{b}}$ & $33.08 \pm 5.88^{\mathrm{b}}$ \\
$\mathrm{C}+\mathrm{G}$ & 16 & $1.64 \pm 0.039^{\mathrm{a}, \mathrm{b}}$ & $14.26 \pm 2.66^{\mathrm{a}, \mathrm{b}}$ & $62.81 \pm 9.55^{\mathrm{a}, \mathrm{b}}$ \\
\hline
\end{tabular}

Data are presented as means $\pm \mathrm{SD}$, No., number of mice in the group; RI, renal index; BUN, blood urea nitrogen level; Scr, serum creatinine level; N, control group; C, cisplatin (CP) group; G, grape seed proanthocyanidin extract (GSPE) group; $\mathrm{C}+\mathrm{G}, \mathrm{CP}+\mathrm{GSPE}$ group; ${ }^{\mathrm{s}} \mathrm{statistically}$

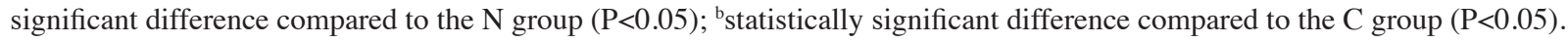
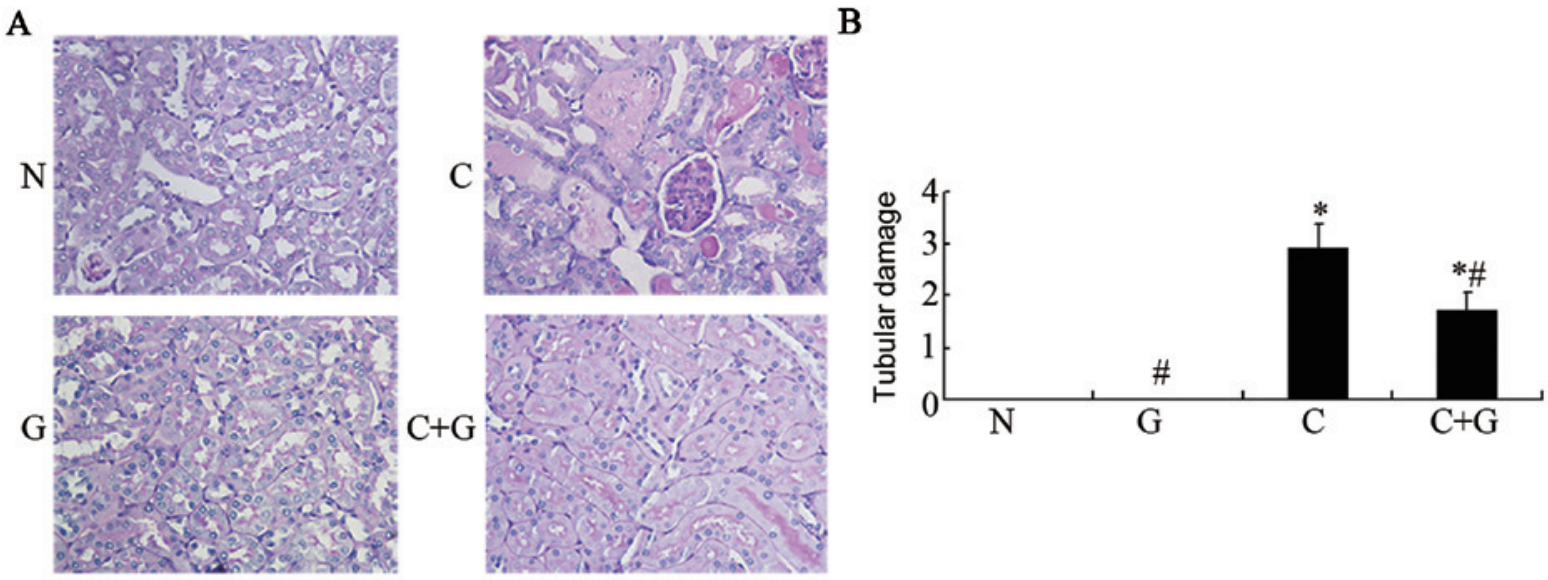

Figure 1. Grape seed proanthocyanidin extract (GSPE) protects from cisplatin (CP)-induced acute kidney injury. Animals were divided into four groups: the control group (N), the CP group (C), the GSPE group (G) and the CP+GSPE group (C+G). (A) Microscopic examination of sections stained with PAS at $x 400$ magnification. The structure of the kidney was normal in the N and G groups. In the C group, brush border damage, renal tubular epithelial cell swelling, degeneration, necrosis, tubular casts and degeneration of cell vacuoles were observed. The $\mathrm{C}+\mathrm{G}$ group showed no or very little structural damage. (B) Scores of tubular damage. Data are presented as means \pm SD. "Statistically significant difference compared to the $\mathrm{N}$ group $(\mathrm{P}<0.05)$; ${ }^{*}$ statistically significant difference compared to the $\mathrm{C}$ group $(\mathrm{P}<0.05)$.

Protein sample preparation. The tissue samples were homogenized in TRIzol (50-100 $\mathrm{mg} / \mathrm{ml}$ TRIzol). Following the addition of chloroform $(0.2 \mathrm{ml} / \mathrm{ml}$ TRIzol $)$, the homogenates were centrifuged at $12,000 \mathrm{x}$ g for $15 \mathrm{~min}$ at $4^{\circ} \mathrm{C}$. Supernatants were discarded, isopropanol $(1.5 \mathrm{ml} / \mathrm{ml}$ TRIzol) was added to the lower phase, followed by centrifugation at 12,000 x $\mathrm{g}$ for $15 \mathrm{~min}$ at $4^{\circ} \mathrm{C}$. The pellets were washed with $0.3 \mathrm{M}$ guanidine hydrochloride $(2 \mathrm{ml} / \mathrm{ml}$ TRIzol) three times, then dissolved in $1 \% \operatorname{SDS}(100 \mu \mathrm{l} \mathrm{SDS} / \mathrm{ml} \mathrm{TRIzol})$ at $50^{\circ} \mathrm{C}$ for $30 \mathrm{~min}$. Protein concentrations were determined using the Pierce BCA Protein Assay kit (Thermo Fisher Scientific Inc., Rockford, IL, USA).

Western blotting. Proteins (50 $\mu \mathrm{g})$ were subjected to $10-12 \%$ SDS-polyacrylamide gel electrophoresis, and gels were transferred to cellulose acetate membranes. The membranes were blocked with $5 \%$ skim milk at room temperature for $1 \mathrm{~h}$, then incubated with primary antibodies (anti-GRP78 1:250, antip-ERK 1:1,000, anti-ERK 1:1,000, anti-caspase-12 1:500 and anti- $\beta$-actin $1: 2,500$ ) at $4^{\circ} \mathrm{C}$ overnight. After a 1 -h incubation with secondary antibodies at room temperature, the membranes were immersed in enhanced chemiluminescence (ECL) reagent and exposed to an X-ray film. Quantification of the luminosity of each protein band was performed using Adobe Photoshop software (Adobe Photoshop 7.0, Adobe, San Jose,
CA, USA). GRP78, p-ERK and caspase-12 relative quantities were expressed as a ratio of luminosity of the respective sample to that of the $\mathrm{N}$ group.

Statistical analysis. Data are presented as means \pm SD. Differences between groups were evaluated using analysis of variance (ANOVA) or Mann-Whitney U-tests. Differences were considered statistically significant at $\mathrm{P}<0.05$.

\section{Results}

GSPE protects from $C P$-induced AKI. As shown in Table I, 8 mice out of 10 survived in the $\mathrm{N}$ group, 15 mice out of 20 survived in the CP group, 13 out of 15 survived in the GSPE group, and 16 out of 20 survived in the CP+GSPE group. The levels of BUN, Scr and RI were significantly increased in the $\mathrm{CP}$ group compared to the control group $(\mathrm{P}<0.05)$. Compared to the CP group, the levels of BUN, Scr and RI were significantly decreased in the CP+GSPE group $(\mathrm{P}<0.05)$. The levels of BUN, Scr and RI in the GSPE group did not show significant differences compared to the control group.

Results from histopathological examinations following PAS staining are shown in Fig. 1A. We observed brush border damage, renal tubular epithelial cell swelling, degeneration, 

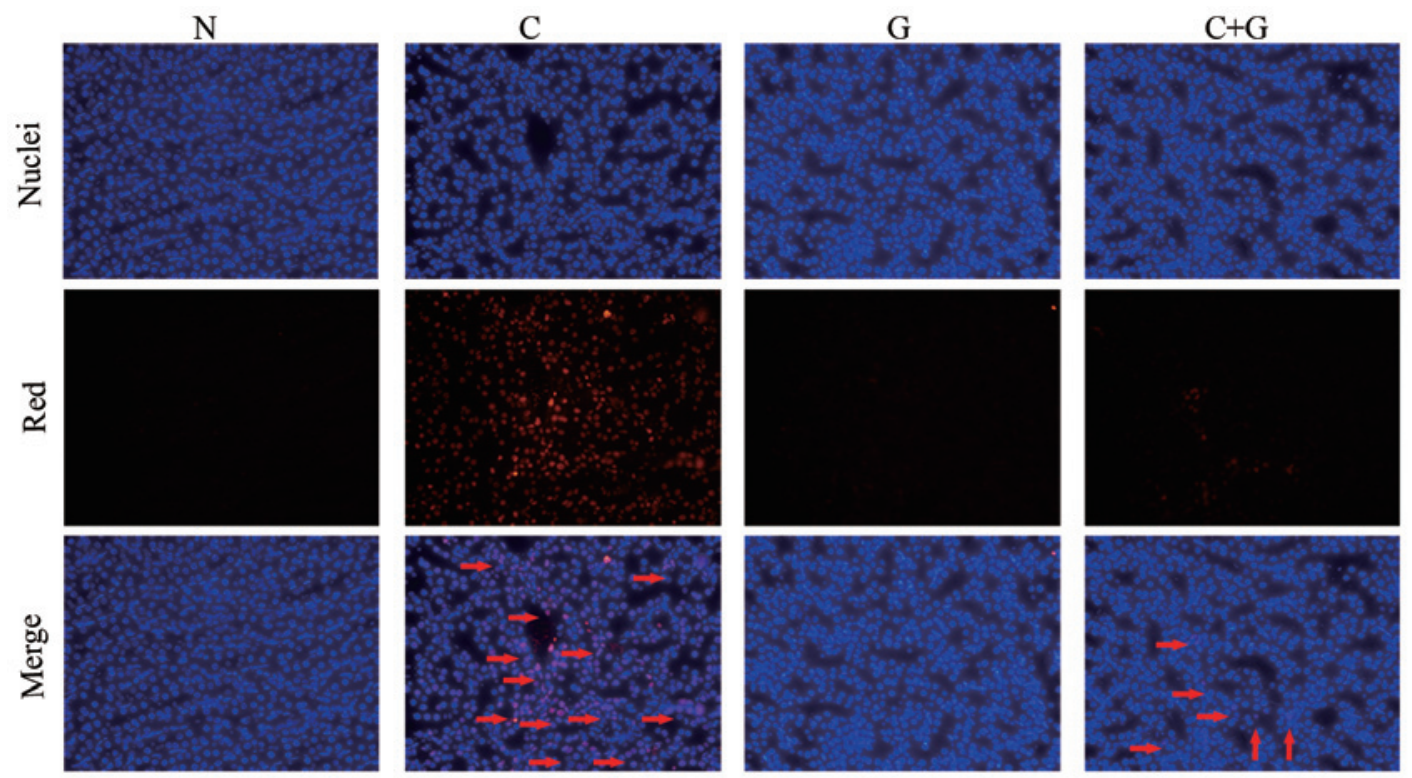

Figure 2. Grape seed proanthocyanidin extract (GSPE) protects from proximal tubular cell apoptosis induced by cisplatin. Arrows on the merge panel show the superposition of nuclear staining to TUNEL (red) staining and represent TUNEL-positive cells. Magnification, x400. Animals were divided into four groups: the control group $(\mathrm{N})$, the cisplatin $(\mathrm{CP})$ group $(\mathrm{C})$, the GSPE group $(\mathrm{G})$ and the $\mathrm{CP}+\mathrm{GSPE}$ group $(\mathrm{C}+\mathrm{G})$.

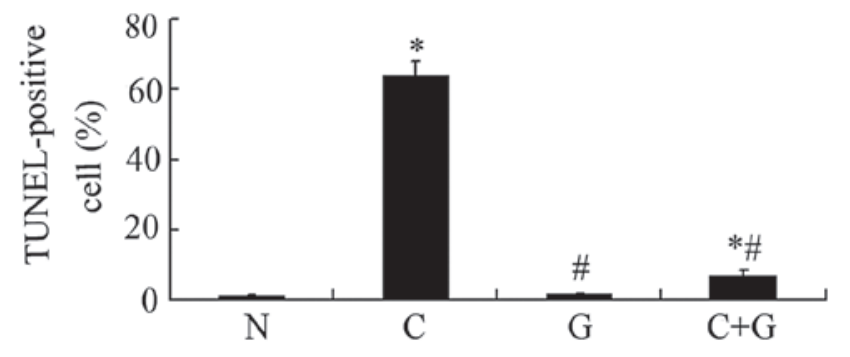

Figure 3. Grape seed proanthocyanidin extract (GSPE) protects from proximal tubular cell apoptosis induced by cisplatin. Animals were divided into four groups: the control group $(\mathrm{N})$, the cisplatin $(\mathrm{CP})$ group $(\mathrm{C})$, the GSPE group $(\mathrm{G})$ and the $\mathrm{CP}+\mathrm{GSPE}$ group $(\mathrm{C}+\mathrm{G})$. "Statistically significant difference compared to the $\mathrm{N}$ group $(\mathrm{P}<0.05)$; " statistically significant difference compared to the $\mathrm{C}$ group $(\mathrm{P}<0.05)$.

necrosis, tubular casts and cell vacuole degeneration in the proximal tubules of kidney in the $\mathrm{CP}$ group, while in the control and GSPE groups, the kidneys maintained normal structure. Compared to the CP group, tubular damage was greatly improved in the CP+GSPE group. We further calculated scores of tubular damage as shown in Fig. 1B. The CP group had an injury score of 2.9 , while the CP+GSPE group scored 1.7, and this difference was significant $(\mathrm{P}<0.05)$, indicating that GSPE can block the renal injury caused by $\mathrm{CP}$.

GSPE inhibits apoptosis induced by CP. To assess whether GSPE protects proximal tubular cell apoptosis induced by $\mathrm{CP}$, the tissue sections were labeled with an in situ TUNEL assay. As shown in Fig. 2, renal tubular epithelial cells undergoing apoptosis were stained red. The CP group showed a high number of TUNEL-positive cells compared to the control group $(\mathrm{P}<0.05)$. The TUNEL-positive cells were significantly reduced in the $\mathrm{CP}+\mathrm{GSPE}$ group compared to the CP group $(\mathrm{P}<0.05)$. Limited apoptosis was detected in the control and the GSPE group (Fig. 3).
GSPE inhibits expression of GRP78, p-ERK and caspase-12. Apoptosis occurred in the proximal tubular cells of the $\mathrm{CP}$ group. In order to investigate whether GSPE protects from $\mathrm{CP}$-induced nephrotoxicity by attenuating ER stress-induced apoptosis in proximal tubular cells, we examined the expression of GRP78, p-ERK and caspase-12, which are important protein players in ER stress-induced apoptosis. Expression of these proteins was studied by western blotting and immunohistochemistry. The two approaches showed that GRP78, p-ERK and caspase-12 are highly expressed in the CP group, while their levels are significantly reduced in the CP+GSPE group $(\mathrm{P}<0.05)$ (Figs. 4-6). These proteins showed limited expression in the control and GSPE groups.

\section{Discussion}

$\mathrm{CP}$ is an antineoplastic drug widely used in the clinic, with obvious curative effects, especially in the treatment of solid-organ tumors; however, nephrotoxicity represents a major dose-limiting side-effect of CP (1). The pathogenesis of CP-induced nephrotoxicity is associated with several factors, including inflammation, oxidative stress, DNA damage, mitochondrial dysfunction and apoptosis $(3,6,14,15)$. Different pathways of apoptosis have been studied in this respect, including the intrinsic and extrinsic pathways (7). It was recently suggested that ER stress-mediated apoptosis is an important pathway in renal apoptosis (16).

In this study, the $\mathrm{CP}$ group showed a significant increase in the level of BUN, $\mathrm{Cr}$ and RI compared to the control group. Histopathological examination showed that the CP group has significant structural damage compared to the control group. The number of TUNEL-positive cells was significantly increased in the $\mathrm{CP}$ group compared to the $\mathrm{N}$ group. These results are consistent with those from previous studies $(17,18)$. By contrast, the $\mathrm{CP}+\mathrm{GSPE}$ group showed a significant decrease in the levels of BUN, $\mathrm{Cr}$ and RI compared to the $\mathrm{CP}$ group. 

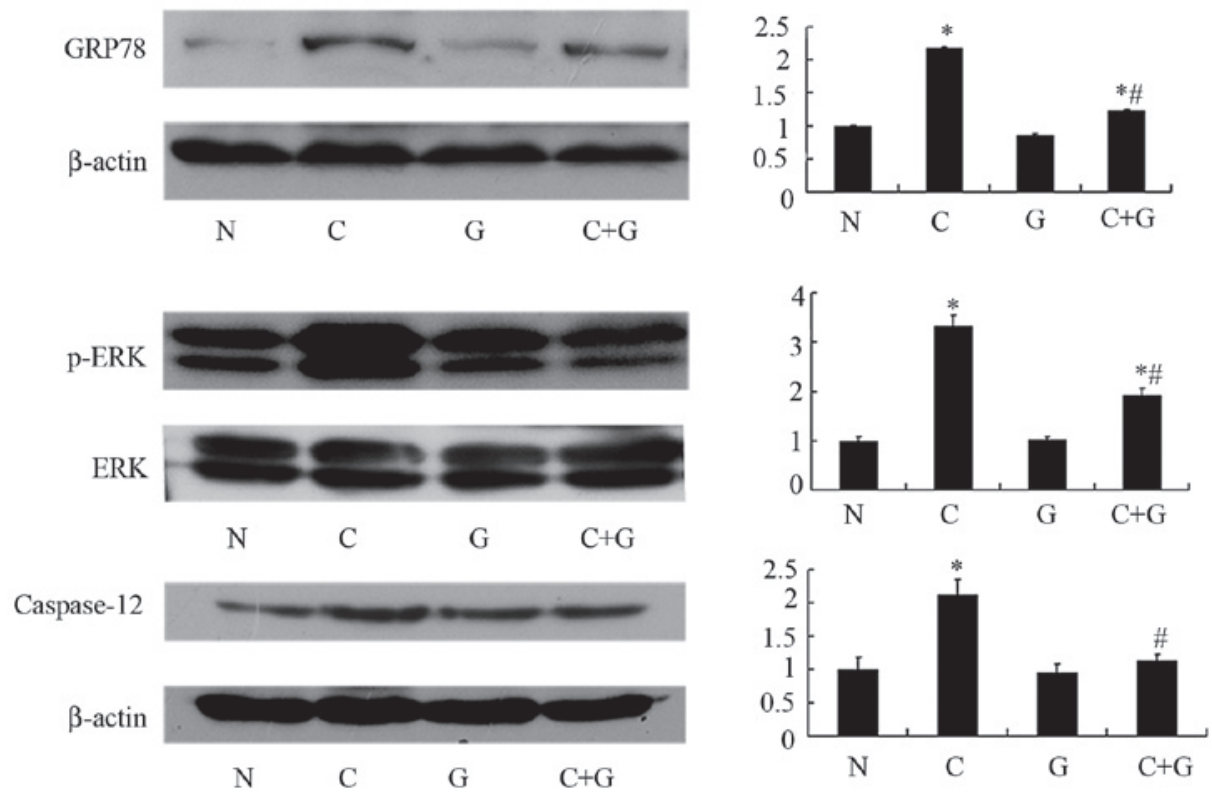

Figure 4. Western blot analysis for GRP78, p-ERK and caspase-12, and quantification of corresponding protein levels. Animals were divided into four groups: the control group $(\mathrm{N})$, the cisplatin $(\mathrm{CP})$ group $(\mathrm{C})$, the grape seed proanthocyanidin extract (GSPE) group $(\mathrm{G})$ and the $\mathrm{CP}+\mathrm{GSPE}$ group $(\mathrm{C}+\mathrm{G})$. Data are expressed as mean \pm SD levels relative to $\beta$-actin. "Statistically significant difference compared to the $\mathrm{N}$ group $(\mathrm{P}<0.05) ;{ }^{*}$ statistically significant difference compared to the $\mathrm{C}$ group $(\mathrm{P}<0.05)$
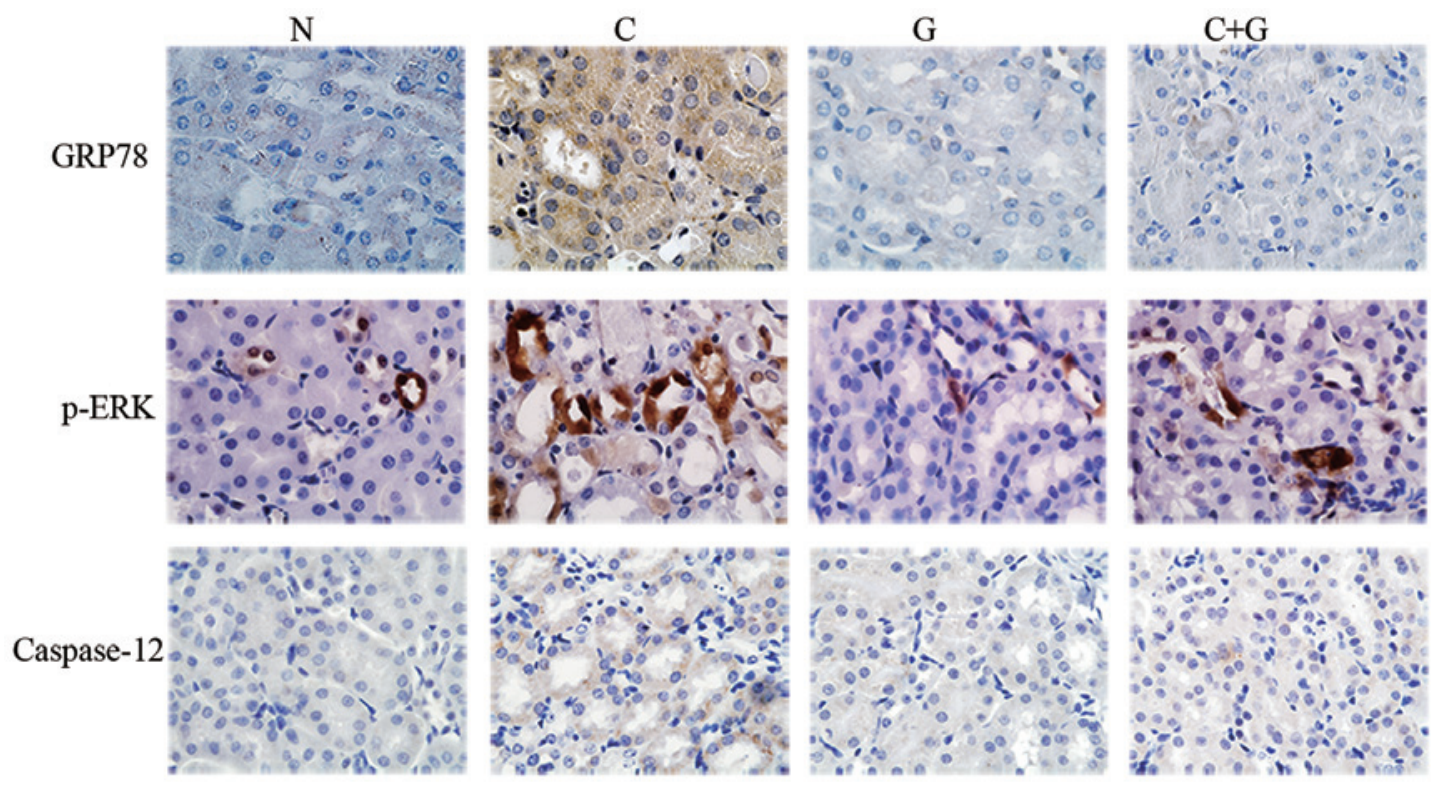

Figure 5. Immunohistochemical staining of GRP78, p-ERK and caspase-12 in the kidney. Animals were divided into four groups: the control group (N), the cisplatin $(\mathrm{CP})$ group $(\mathrm{C})$, the grape seed proanthocyanidin extract (GSPE) group $(\mathrm{G})$ and the $\mathrm{CP}+\mathrm{GSPE}$ group $(\mathrm{C}+\mathrm{G})$. The brown granules represent positively-stained cells. Magnification, x1,000.

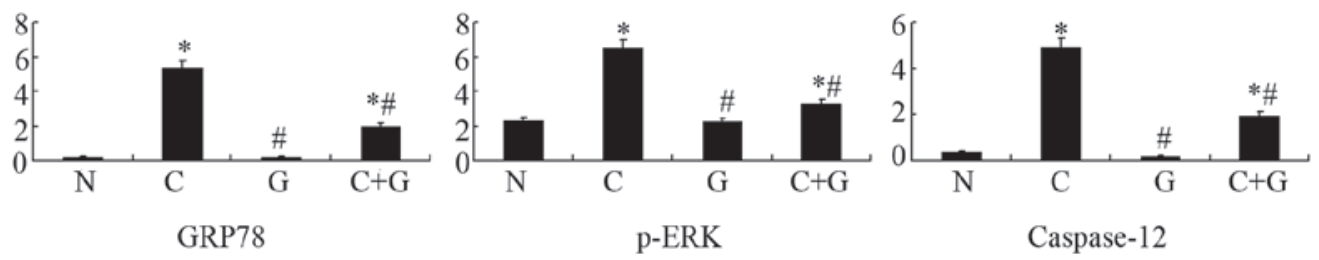

Figure 6. Semi-quantitative analysis of immunohistochemical staining of GRP78, p-ERK and caspase-12 in the kidney, based on the percentage of positively stained areas in the tubules and the intensity of staining. Animals were divided into four groups: the control group (N), the cisplatin (CP) group (C), the grape seed proanthocyanidin extract (GSPE) group (G) and the CP+GSPE group (C+G). The expression of GRP78, p-ERK and caspase-12 was significantly increased in the $\mathrm{C}$ group compared to the $\mathrm{N}$ group and significantly decreased in the $\mathrm{C}+\mathrm{G}$ group compared to the $\mathrm{C}$ group. . Statistically significant difference compared to the $\mathrm{N}$ group $(\mathrm{p}<0.05)$; " statistically significant difference compared to the $\mathrm{C}$ group $(\mathrm{p}<0.05)$. 
Histopathology also showed that the CP+GSPE group has very limited structural damage. The number of TUNEL-positive cells was significantly reduced in the CP+GSPE group compared to the CP group. This indicates that GSPE can inhibit the apoptosis of renal tubular epithelial cells induced by $\mathrm{CP}$ and may thus improve the renal dysfunction. The mechanism by which GSPE protects from CP-induced nephropathy involves its antioxidant properties $(19,20)$. It has been shown that oxidative stress proteins are downregulated by GSPE in diabetic nephropathy $(12,13)$. GSPE is a highly efficient natural antioxidant extracted from natural grape seeds. Its antioxidant activity is 50 times higher than that of vitamin $\mathrm{E}$ and 20 times that of vitamin C. It has also been shown that GSPE has powerful anti-inflammatory effects, which can be used in the treatment and prevention of diseases (21-27). Recent studies provided evidence that GSPE may serve as a useful agent in the prevention of diseases such as atherosclerosis, gastric ulcer, cataract, diabetes, and can also protect from methylmercuryinduced neurotoxicity $(13,28)$. In addition, GSPE is known to modulate apoptosis (29). A recent study found that the apoptosis caused by the ER stress pathway plays an important role in CP-induced nephropathy (18). Therefore, CP can lead to apoptosis of the renal tubular epithelial cells by inducing ER stress.

ER stress can be caused by a number of factors such as ischemia, hyperglycemia, hypoxia and heat shock (10). GRP78 is an important molecular chaperone, localized in the ER and extensively used as an indicator of ER stress induction (16). The phosphorylated-extracellular signal-regulated kinase (p-ERK) has an early and crucial role in cell protection and survival during stress, even mild (10). p-ERK is a transmembrane ER protein involved in signal transduction. In the inactive state, ERK and two additional ER-stress sensor proteins, IRE-1 and ATF6, are associated with the ER chaperone Grp78/BiP. When the levels of unfolded and/or misfolded proteins increase, ERK and ER-stress sensors dissociate from Grp78/BiP, and activate downstream molecules (30). The extracellular signal-regulated kinase (ERK) has been shown to mediate CP-induced toxicity in renal proximal tubule cells (31). Caspase-12 plays a key role in ER stress-induced apoptosis (32). Caspase-12 is a marker of apoptosis and specifically localizes in the ER. It was previously demonstrated that caspase-12-mediated apoptosis is specific to ER, and that caspase- 12 cannot be activated when apoptosis occurs via membrane or mitochondrial signals (33). Thus, GRP78 and p-ERK are protein markers of ER stress and caspase-12 is a marker of ER stress-induced apoptosis.

To determine the mechanism by which GSPE protects tubular cells from CP-induced apoptosis, the protein levels of GRP78, p-ERK and caspase-12 were measured. GRP78, p-ERK and caspase-12 were highly expressed in CP-treated mice that showed important structural alterations in the kidney, indicating that $\mathrm{CP}$-induced nephropathy involves ER stress-induced apoptosis. GSPE can attenuate ER stress-induced apoptosis, as evidenced in the present study by the significant reduction in the levels of GRP78, p-ERK and caspase-12, observed following administration of the extract. The present results suggest that exposure to $\mathrm{CP}$ activates ER stress-regulated survival and apoptotic signaling pathways in renal tubular cells. Moreover, we present evidence that the caspase-12-dependent apoptotic pathway may be involved in
CP-induced nephropathy. The reduction in the expression of GRP78, p-ERK and caspase-12 caused by GSPE demonstrates that GSPE can attenuate ER stress-induced apoptosis via the caspase-12-dependent pathway.

In conclusion, this study showed that GSPE can protect from CP-induced AKI. The underlying mechanism involves the inhibition of ER stress-mediated apoptosis via the caspase12-dependent pathway. These results suggest that GSPE can be applied to treat CP-induced nephropathy.

\section{Acknowledgements}

This study was supported by the National Natural Science Foundation of China (grant no. 81200529), the Natural Science Foundation of Shandong Province (grant no. ZR2012HQ001) and the Independent Innovation Foundation of Shandong University (IIFSDU; grant no. 2012TS167).

\section{References}

1. Miller RP, Tadagavadi RK, Ramesh G and Reeves WB: Mechanisms of cisplatin nephrotoxicity. Toxins 2: 2490-2518, 2010.

2. Arany I and Safirstein RL: Cisplatin nephrotoxicity. Semin Nephrol 23: 460-464, 2003.

3. Yao X, Panichpisal K, Kurtzman N and Nugent K: Cisplatin nephrotoxicity: a review. Am J Med Sci 334: 115-124, 2007.

4. Cohen SM and Lippard SJ: Cisplatin: from DNA damage to cancer chemotherapy. Prog Nucleic Acid Res Mol Biol 67: 93-130, 2001

5. Hanigan $\mathrm{MH}$ and Devarajan P: Cisplatin nephrotoxicity: molecular mechanisms. Cancer Ther 1: 47-61, 2003.

6. Brady HR, Kone BC, Stromski ME, Zeidel ML, Giebisch G and Gullans SR: Mitochondrial injury: an early event in cisplatin toxicity to renal proximal tubules. Am J Physiol 258: 1181-1187, 1990.

7. Pabla N and Dong Z: Cisplatin nephrotoxicity: mechanisms and renoprotective strategies. Kidney Int 73: 994-1007, 2008.

8. Liu GH, Sun YY, Li ZH, et al: Apoptosis induced by endoplasmic reticulum stress involved in diabetic kidney disease. Biochem Biophys Res Commun 370: 651-656, 2008.

9. Schroder M and Kaufman RJ: The mammalian unfolded protein response. Annu Rev Biochem 74: 739-789, 2005.

10. Szegezdi E, Logue SE, Gorman AM and Samali A: Mediators of endoplasmic reticulum stress-induced apoptosis. EMBO Rep 7: 880-885, 2006.

11. Cheng M, Gao HQ, Xu L, Li BY, Zhang $\mathrm{H}$ and Li XH: Cardioprotective effects of grape seed proanthocyanidins extracts in streptozocin induced diabetic rats. J Cardiovasc Pharmacol 50: 503-509, 2007.

12. Li BY, Cheng M, Gao HQ, et al: Back-regulation of six oxidative stress proteins with grape seed proanthocyanidin extracts in rat diabetic nephropathy. J Cell Biochem 104: 668-679, 2008.

13. Li X, Xiao Y, Gao H, et al: Grape seed proanthocyanidins ameliorate diabetic nephropathy via modulation of levels of AGE, RAGE and CTGF. Nephron Exp Nephrol 111: 31-41, 2009.

14. Leibbrandt ME, Wolfgang GH, Metz AL, Ozobia AA and Haskins JR: Critical subcellular targets of cisplatin and related platinum analogs in rat renal proximal tubule cells. Kidney Int 48: 761-770, 1995.

15. Kharbanda S, Ren R, Pandey P, et al: Activation of the c-Abl tyrosine kinase in the stress response to DNA-damaging agents. Nature 376: 785-788, 1995.

16. Lakshmanan AP, Thandavarayan RA, Palaniyandi SS, et al: Modulation of AT-1R/CHOP-JNK-Caspase12 pathway by olmesartan treatment attenuates ER stress-induced renal apoptosis in streptozotocin-induced diabetic mice. Eur J Pharm Sci 44: 627-634, 2011.

17. Wei Q, Dong G, Franklin J and Dong Z: The pathological role of Bax in cisplatin nephrotoxicity. Kidney Int 72: 53-62, 2007.

18. Kong DY, Li Z, Gao CL, et al: Erythropoietin protects against cisplatin-induced nephrotoxicity by attenuating endoplasmic reticulum stress-induced apoptosis. J Nephrol 26: 219-227, 2013. 
19. Cetin A, Arslanbas U, Saraymen B, Canoz O, Ozturk A and Sagdic O: Effects of grape seed extract and origanum onites essential oil on cisplatin-induced hepatotoxicity in rats. UHOD 21: 133-140, 2011

20. Sayed AA: Proanthocyanidin protects against cisplatin-induced nephrotoxicity. Phytother Res 23: 1738-1741, 2009.

21. Chacon MR, Arola L and Guitierrez C: Grape-seed procyanidins modulate inflammation on human differentiated adipocytes in vitro. Cytokine 47: 137-142, 2009.

22. Cho ML, Heo YJ, Park MK, et al: Grape seed proanthocyanidin extract (GSPE) attenuates collagen induced arthritis. Immunol Lett 124: 102-110, 2009.

23. Johnson VL, Brodsky N and Bhandari V: Effect of antioxidants on apoptosis and cytokine release in fetal rat Type II pneumocytes exposed to hyperoxia and nitric oxide. Cytokine 28: 10-16, 2004

24. Ma L, Gao HQ, Li BY, Ma YB, You BA and Zhang FL: Grape seed proanthocyanidin extracts inhibit vascular cell adhesion molecule expression induced by advanced glycation end products through activation of peroxisome proliferators-activated receptor gamma. J Cardiovasc Pharmacol 49: 293-298, 2007.

25. Terra X, Montagut G, Bustos M, et al: Grape-seed procyanidins prevent low-grade inflammation by modulating cytokine expression in rats fed a high-fat diet. J Nutr Biochem 20: 210-218, 2009.

26. Sen CK and Bagchi D: Regulation of inducible adhesion molecule expression in human endothelial cells by grape seed proanthocyanidin extract. Mol Cell Biochem 216: 1-7, 2001.
27. Kim H, Kim JY, Song HS, Park KU, Mun KC and Ha E: Grape seed proanthocyanidin extract inhibits interleukin-17-induced interleukin-6 production via MAPK pathway in human pulmonary epithelial cells. Naunyn Schmiedebergs Arch Pharmacol 383: 555-562, 2011.

28. Yang HB, Xu ZF, Liu W, et al: Effect of grape seed proanthocyanidin extracts on methylmercury-induced neurotoxicity in rats. Biol Trace Elem Res 147: 156-164, 2012.

29. Cedó L, Auvi AC, Pallares V, et al: Grape seed procyanidin extract modulates proliferation and apoptosis of pancreatic beta-cells. Food Chemistry 138: 524-530, 2013

30. van der Kallen CJ, van Greevenbroek MM, Stehouwer CD and Schalkwijk CG: Endoplasmic reticulum stress-induced apoptosis in the development of diabetes: is there a role for adipose tissue and liver? Apoptosis 14: 1424-1434, 2009.

31. Clark JS, Faisal A, Baliga R, Nagamine Y and Arany I: Cisplatin induces apoptosis through the ERK-p66she pathway in renal proximal tubule cells. Cancer Lett 297: 165-170, 2010.

32. Szegezdi E, Fitzgerald U and Samali A: Caspase-12 and ER-stress-mediated apoptosis: the story so far. Ann NY Acad Sci 1010: 186-194, 2003.

33. Nakagawa T, Zhu H, Morishima N, et al: Caspase-12 mediates endoplasmic-reticulum-specific apoptosis and cytotoxicity by amyloid- $\beta$. Nature 403: 98-103, 2000. 